\title{
Marshall Sahlins ou por uma antropologia estrutural e histórica
}

\author{
LILIA MORITZ SCHWARCZ"
}

A Antropologia, desde seu nascimento institucional, estabeleceu relações tensas e, muitas vezes, pouco cordiais com a História. Sobretudo no campo da Antropologia, a necessária contraposição com a História pareceu vincular-se à própria definição da disciplina, que precisava, de alguma maneira, diferenciar-se para compor um campo mais definido de atuação.

Não é por mera coincidência que, nas obras mais tradicionais da disciplina, a História tenha surgido contraposta à Antropologia ou à, assim chamada, Etnologia. Seja por alegações de método - pesquisa em arquivos por um lado, pesquisa participante, por outro; de objeto - viajantes no tempo versus viajantes no espaço; de procedimento - a pesquisa da classe dirigente por oposição ao cstudo das manifestações populares; ou de objetivos - o evento no lugar da cultura e de seus rituais; o fato é que divisões mais ou menos frágeis foram sendo levantadas, no sentido de se constituírem limites evidentes ou identidades particulares a cada uma das áreas. Dicotomias ainda mais rígidas estabeleceram-se, aos poucos, guardando para a História o reino da diacronia e do tempo volátil e para a Antropologia o lugar da sincronia e da estrutura.

* Professora do Departamento de Antropologia da USP.
Foi assim que na tradição antropológica a questão da diacronia mobilizou escolas e autores, mesmo que para se destacar dela. Nesse último caso, "enfrentar o tempo" e recorrer a ele, fez parte da própria trajetória da disciplina. Com efeito, se os primeiros antropólogos evolucionistas de alguma maneira introduziram a temporalidade em sua concepção - apesar de impor uma noção etapista e serial -, os demais acabaram fazendo da disciplina uma espécie de anti-história.

Segundo uma perspectiva mais consensual caberia ao antropólogo, em uma divisão mais positiva, o lugar da ausência do tempo, suprido pelo aporte ao presente. Mas como não se constrói uma disciplina por um recorte - o recurso ao presente ou ao passado - o certo é que distinções desse tipo tenderão a ser menosprezadas, frente à determinação de que o tempo não é só um objeto, mas sobretudo uma dimensão cultural da vida social.

Fiquemos ainda um pouco mais nos meandros desse debate. É o próprio Lévi-Strauss quem fará toda uma "História da Antropologia”, em seu polêmico ensaio Etnologia $e$ História (1975), publicado pela primeira vez em 1949. Nesse texto - que se tornou uma espécie de símbolo desse embate - o índice de clivagem entre as várias escolas antropológicas remete ao uso ou não da diacronia, levando-se sempre em consideração que a noção de "tempo", pensada como representação da his- 
tória, está presente em toda e qualquer sociedade, como condição de inteligibilidade, mas também como marca de diferença.

Vale a pena retomar, mesmo que de forma breve, a trajetória elaborada por Lévi-Strauss, com vistas a entender como esse diálogo foi se constituindo de maneira tensa. Com efeito, segundo o etnólogo francês, esse enfrentamento teria começado com uma "recusa".

Por um lado, já na perspectiva culturalista, a descoberta de que os documentos encontrados nas sociedades estudadas pelos antropólogos desencorajariam qualquer historiador a analisá-los fez com que se reconhecesse uma distinção, pautada na ausência de materiais e dados comprovatórios. Segundo Lévi-Strauss, Boas manifestara a decepção de ter de renunciar à aspiração de compreender "como as coisas chegaram a ser o que são"; ou seja, renunciar a compreender a história para fazer do estudo das culturas uma análise sincrônica das relações entre seus elementos constitutivos, no presente. O problema que "espezinhava" Lévi-Strauss era saber se era possível fazer história do presente sem recurso ao passado; entender uma cultura única, sem recuar a seu processo e sem transformar a (ausência de) história em a "nossa história": numa única temporalidade.

Na opinião do etnólogo francês, ainda, foi em nome dessa "falência" que se abriu mão, na escola inglesa e sobretudo com Malinowski, de qualquer história. Adeptos de um modelo sincrônico de análise, os funcionalistas defenderam que toda pesquisa antropológica deveria proceder de um estudo minucioso de sociedades concretas. Malinowski e seus seguidores perguntaram-se acima de tudo sobre a questão da "função", entendida como instrumento para desvendar sociedades aparentemente caóticas. Dessa maneira, partindo do suposto de que o que o etnógrafo faz é estudar como as sociedades se mantêm, e não como se modificam, essa escola notou nos grupos selecionados exemplos de funcionalidade e nas instituições destacadas modelos de coesão e de reposição do equilíbrio. Portanto, diante de uma história conjectural, armou-se um modelo de base empírica, imune à história e a seu desenvolvimento. De toda forma, a descoberta de leis de mudança social deveria basear-se no estudo de processos presentes, único caminho para que a Antropologia se convertesse numa ciência generalizante, conforme o modelo das ciências naturais.

Concluía Lévi-Strauss nesse mesmo ensaio: “espera-se por um milagre inaudito ... com a única condição suplementar de fechar resolutamente os olhos a toda informação histórica relativa à sociedade ..." (1975:26). Na verdade, privando-se de qualquer história, Malinowski teria abandonado a própria temporalidade das culturas, parte fundamental na percepção de sua especificidade.

Também Radcliffe-Brown, em sua defesa de um estudo comparativo e generalizante, ao qual denominou de "Antropologia Social", expulsou a história da reflexão disciplinar. Segundo esse antropólogo, diante da falta de documentos escritos o melhor era optar pela "a-historicidade", concluindo que tal método só levaria a proposições particulares e conjecturas parciais. No entanto, nas objeções desses dois autores (cada um à sua maneira) estava presente uma visão por demais positivada da história e de seus documentos, cuja legitimidade só poderia ser garantiria a partir da descoberta de manuscritos. Além disso, é no mínimo ingênuo supor que não existiria temporalidade no momento atual. Como diz Lévi-Strauss: "Quando nos limitamos ao instante presente da vida de uma sociedade, somos antes de tudo vítimas de uma ilusão: pois tudo é história; o que foi dito ontem é história, o que foi dito há um minuto é história. Mas, sobretudo, condenamo-nos a não conhe- 
cer o presente ... E muito pouca história (já que tal é infelizmente o quinhão do etnólogo) vale mais do que nenhuma" (1975:26-7).

Nas críticas de Lévi-Strauss à escola estrutural-funcionalista inglesa é possível imaginar não tão-somente um questionamento teórico, como, também, uma tentativa de, por meio da oposição, construir um método. Pela contraposição problematizavam-se os estudos empíricos, assim como era possível "relativizar a relatividade cultural", na busca do comum imerso no diferente. Deixemos, porém, a análise mais aprofundada dessa escola um pouco de lado, a fim de retomar o debate com a História e com o próprio estruturalismo, que sempre se definiu a partir de uma perspectiva sincrônica.

Apesar da pecha, já em seus primeiros estudos, como Raça e História (1952), LéviStrauss não só analisou "histórias diferentes" - estacionárias e cumulativas -, que mais tarde chamou de "frias ou quentes", como indicou nuanças e gradações: os dois modelos de história não revelariam a existência ou não de história, mas, sim, o fato de algumas sociedades se representarem a partir da história e outras não. Estaríamos, mais uma vez, no domínio das historicidades e da noção de que diferentes sociedades constróem o tempo, ou não, a partir de suas cosmologias particulares.

Mas voltemos mais uma vez ao ensaio de Lévi-Strauss, dessa vez com o objetivo de definir seu próprio método. Com efeito, após ter passado a limpo a Antropologia de até então, o etnólogo chega a seu dilema fundamental: "Pretender reconstituir um passado do qual se é impotente para atingir a história, ou querer fazer a história de um presente sem passado, drama da etnologia em um caso, da etnografia de outro" (1975:30). Como se pode notar, a diferença entre disciplinas vai se tornando cada vez mais estrita. O problema não parece ser de objeto (na medida em que ambas procuram a alteridade), muito menos de obje- tivo (que passa a ser o diverso), nem mesmo de método. No entanto, a diversidade ficava mantida: "Enquanto a História organiza seus dados em relação às expressões conscientes, a etnologia indaga sobre as relações inconscientes da vida social" (1975:34).

Com essa frase de efeito, Lévi-Strauss lançava as bases de uma Antropologia estrutural e elegia um projeto de caráter universal, como critério de distinção e de propriedade da etnologia. Procurando na lingüística estrutural na busca de invariantes universais e nos processos inconscientes - seus principais alicerces, o autor retomava não só toda a produção antropológica, como, de quebra, desautorizava um certo tipo de historiografia que se construía lado a lado naquele momento ${ }^{1}$.

A História se transformava, assim, numa espécie de marcha regressiva, etapa necessária para que se chegue à finalidade fundamental; qual seja, um inventário das possibilidades inconscientes. Entretanto, o artigo de 1949 terminava com uma espécie de "armistício"; depois de ter demarcado distinções tão fundamentais, nosso autor voltava à boa convivência. Os procedimentos seriam iguais: a passagem, para o historiador, do explícito ao implícito; para o etnólogo, do particular ao universal. Além do mais, a diferença seria sobretudo de orientaçã̃o, não de objeto: “o etnólogo se interessa sobretudo pelo que não é escrito, não tanto porque os povos que estuda são incapazes de escrever, como porque aquilo por que se interessa é diferente de tudo o que os homens se preocupam habitualmente em fixar na pedra ou no papel" (1975:41).

Não obstante, a polêmica já estava instaurada e reificava a separação entre sincro-

1. Não se pode esquecer que, nesse mesmo momento, na França, a Escola dos Annales buscava parâmetros semelhantes ao eleger "o problema" e a interdisciplinaridade como temas fundamentais para suas investigações. 
nia e diacronia; estrutura e história. O suposto era que não havia como lidar com diacronias estanques, que abririam campos diversos e perspectivas quase antagônicas.

Certos adendos devem ser feitos. Em primeiro lugar, Lévi-Strauss costuma ser melhor leitor de si do que de outras escolas e, dessa maneira, suas interpretações sobre a "História da Antropologia" levam sempre ao estruturalismo. Além disso, desde os anos 70 foram muitas as contribuições, que se dividiram entre aquelas que se opuseram, francamente, ao modelo estrutural e outras que seguiram o mestre francês - de mais longe ou mais perto. Não é hora de listar os autores que tomaram parte desse debate, mas o que se pode dizer, sem medo de errar, é que nessa "contenda" Marshall Sahlins merece um lugar especial. Definindo-se como uma espécie de "estruturalista histórico", Sahlins guarda, no campo da Antropologia, um papel de mediador; um bom mediador.

Em primeiro lugar, a partir de seus trabalhos a temporalidade é retomada em sua dimensão social, não sendo mais possível separar sincronia e diacronia. Nota-se, ainda, como a tentativa de "dar história à estrutura”, implicou em uma reavaliação do tema do poder e na utilização do conceito de estrutura em domínios e análises que destacam não a permanência, mas antes a mudança. É isso que faz Marshall Sahlins quando indaga pela existência de estruturas históricas; cosmologias que são reordenadas historicamente.

Já em Cultura e Razão Prática a atenção do autor parecia voltar-se em direção à defesa da "interpretação simbólica da cultura" e para a crítica de sua visão utilitária e intencional. Questionando as explicações pragmáticas, que ignoram o código cultural que governa a utilidade, Sahlins analisou a "autoilusão" de nossa sociedade, que lega a impressão de que a produção não passa de um precipitado, de uma racionalidade esclarecida. O utilitarismo é a maneira pela qual a sociedade ocidental se experimenta e se interpreta, mas não deixa de ser uma explicação da forma cultural.

Insistindo no significado social e cultural dos objetos de uso e da própria troca, Sahlins mostra como a "utilidade não é uma qualidade do objeto, mas uma significação de qualidades objetivas" (Sahlins, 1979:189). É isso que permite concluir a existência de uma razão cultural, uma significação simbólica nos hábitos alimentares, nas práticas vestuárias, nos rituais do cotidiano. Mas se o desenvolvimento desses temas nos levaria a, junto com Sahlins, indagar por que a rainha de copas, em Alice no País das Maravilhas, acabou por concluir que "não se manda cortar a cabeça de alguém que se foi recém-apresentado", mais importa, nesse momento da discussão, enfatizar que, a partir dos trabalhos de Sahlins avançamos com a idéia que os objetos só adquirem sentido quando contextualizados, além de ser possível alargar o espectro estrutural, ao fazê-lo discutir com a História.

Foi em seu livro Historical Metaphors and Mythical Realities - traduzido em parte neste número da Cadernos de Campo-que Sahlins, pela primeira vez, enfrentou esse tipo de terreno pantanoso $e$ interdisciplinar. Como diz o autor: "O grande desafio para uma antropologia histórica é não apenas saber como os eventos são ordenados pela cultura, mas como, nesse processo, a cultura é reordenada. Como a reprodução de uma estrutura se torna a sua transformação?" (2000a:139). Nos termos do autor, o grande desafio era, portanto, não opor de forma mecânica estrutura a história, mas perceber como releituras locais passam sempre por estruturas anteriores. "Basicamente, a idéia é muito simples. As pessoas agem em relação às circunstâncias de acordo com os seus próprios pressupostos cul- 
turais, as categorias socialmente dadas de pessoas e coisas. A pessoa - ação no mundo -, a reavaliação do signo na prática e o retorno à estrutura ... entre sentido simbólico e referência simbólica, o processo histórico se desdobra num movimento contínuo e recíproco entre a prática da estrutura e a estrutura da prática" (2000b:139). "Prática da estrutura, estrutura da prática": aí estaria exposto uma espécie de bordão do autor, que passaria a buscar ambivalências nas lógicas e leituras culturais que acomodam sistemas de longa, curta e média duração. A cultura não é jamais um papel em branco onde se inscrevem modelos vindos de fora. Ao contrário, sua absorção passa pela reavaliação da própria estrutura pela história e vice-versa.

É isso que Sahlins denomina, em Ilhas de História, como "a reavaliação funcional de categorias", nesse movimento que o leva a nuançar dicotomias rígidas que vêm sendo opostas no debate disciplinar: estrutura $\mathrm{X}$ história, sistema $\mathrm{X}$ evento, sincronia $\mathrm{X}$ diacronia, indivíduo $\mathrm{X}$ sociedade, acontecimento $\mathrm{X}$ longa duração. Partindo de uma outra concepção de estrutura, esse autor parece procurar "historicizar a noção de estrutura", advogar a idéia de que é possível pensar em "transformação estrutural" e ao mesmo tempo verificar como as estruturas se realizam no interior da ordem cultural, de alguma maneira destacada do curso histórico.

Partindo da concepção de estrutura de Hocart - e não da noção sincrônica de Saussure, como faz Lévi-Strauss -, Sahlins busca um afastamento do conceito atemporal de estrutura, ao entendê-la como "um conjunto de relações mutuamente contrastante e, por isso mesmo, mutuamente definidora entre signos" (1990:16); tudo isso sem abandonar a história. Com efeito, para esse autor, mesmo na representação mais abstrata de signos - ou seja, na cosmologia - a estrutura está em movimento. Ela possuiria uma diacronia interna, de forma que toda reintrodução já significaria uma reordenação e a sua própria alteração. "A história é ordenada culturalmente de diferentes modos nas diversas sociedades, de acordo com esquemas de significação das coisas, mas o contrário também é verdadeiro: esquemas culturais são ordenados historicamente, porque, em maior ou menor grau, os significados são reavaliados na prática" (ibidem: 38).

O problema levaria, portanto, menos a explodir o conceito de história pela experiência antropológica da cultura (deixemos a tarefa aos historiadores), como a introduzir a experiência histórica estourando o conceito antropológico de cultura e incluindo a estrutura: a transformação de uma cultura é também um modo de sua reprodução. "Estourar o conceito de cultura" significa, nesse caso, repensá-lo de forma a mostrar como ordens culturais diversas têm modos próprios de produção histórica: "culturas diferentes, historicidades diferentes". A cultura, pensada dessa maneira, não é mais do que a organização da situação atual em termos do passado. É a isso que Sahlins chama de "estrutura da conjuntu$r a$ ” - uma síntese entre estrutura e conjuntura -, a maneira como as culturas reagem a um evento (um acortecimento culturalmente significado) fazendo dialogar o contexto imediato com estruturas culturais anteriores, de forma a voltar à máxima de Boas que afirmou que "o olho que vê é o órgão da tradição". A história é, dessa maneira, construída, tanto no interior de uma sociedade, como entre sociedades, que repõem estruturas passadas na orquestração do presente.

Estamos, mais uma vez, diante do velho problema da mediação entre sincronia e diacronia; estrutura e história. Talvez o maior desafio seja abrir mão de modelos que oponham mecanicamente os dois elementos, em 
nome da convivência entre ambos. Só dessa maneira será possível apreender invariantes e permanências estruturais, porém re-significadas (e, portanto, alteradas) em contextos diversos. As categorias alteram-se na ação, mas guardam um diálogo com estruturas culturais anteriores. Eis a noção de dinâmica cultural, que significa pensar que a produção de conteúdo é referida ao contexto, mas re-traduzida em função de modelos anteriores. Isto é, trata-se de selecionar um conjunto de relações históricas que, ao mesmo tempo, reproduzem velhas categorias culturais e lhes dão novos valores retirados de um contexto pragmático.

"A reprodução da estrutura começa com sua própria transformação", afirma Sahlins, que dessa maneira recorta seu próprio objeto: a estrutura da prática e a prática da estrutura. Seja por meio da análise das diferentes recepções que teve o Capitão Cook, das cosmologias do capitalismo, das relações amorosas, dos mastros havaianos... vemos como as estruturas culturais atualizam-se na prática, como se fossem possíveis muitas mortes, diversos capitães, várias explicações. A cultura surge definida como uma ordem estrutural de significação, porém seus conteúdos alteram-se diante da história. Em meio ao contexto contemporâneo, quando se afirma a imposição de um sistema mundial e teme-se a tão falada globalização, o modelo de Sahlins tem o mérito de mostrar que a incorporação do capitalismo em países periféricos se dá, também, de acordo e a partir das distintas lógicas nativas, que geram resultados culturais diversos e, muitas vezes, inesperados. É o "retorno da cultura" que, vista a partir da ótica da recepção, possibilita imaginar que não estaríamos todos condenados, igualmente, à globalização.

A obra de Sahlins sinaliza para rumos recentes da disciplina, que encontram "história na estrutura", fazem dialogar sincronia e dia- cronia e introduzem a questão do poder, até então bastante distante das análises antropológicas. Essa é, sem sombra de dúvida, uma aposta alentada, na medida em que se selecionam objetos históricos, para lá encontrar não apenas o "acontecimento" e a diacronia, mas a sincronia e os elementos de longa duração. $\mathrm{Na}$ explicação do enraizamento de certas simbologias, de rituais e representações, esse tipo de inspiração parece oportuna, na medida em que permite mostrar como os estudos antropológicos, ao procurar por permanências - quase que idiomas locais -, não precisam fechar os olhos à história e à mudança. Por fim, esse tipo de perspectiva dá à Antropologia um local especial no debate contemporâneo, na medida em que revela como a prática política carrega, em sua lógica, dimensões simbólicas e rituais, para além de sua realidade pragmática e imediatamente referida ao contexto.

Mas terminar dessa maneira seria acenar com a bandeira da paz e não olhar para a contenda atual, que inclui o próprio Sahlins. Estou me referindo à polêmicas mais recentes, que têm colocado em questão o estatuto do autor e sua autoridade. Se a "modernidade" - entendida como a afirmação da crise de representação - apareceu em diferentes áreas do conhecimento, foi na Antropologia, talvez em função da proximidade entre sujeito e objeto de análise, que o movimento transformou-se em debate de referência. Sob o rótulo de "pós-modernidade" uma gama extremamente ampla de tópicos e abordagens surgiu na agenda intelectual, levando a repensar modelos, autores e escolas bastante estabelecidos na tradição antropológica. Em questão está o estatuto de conhecimento, a qualidade da investigação e também a questão da responsabilidade política do cientista e do investigado. Não é possível, por certo, desvincular esse debate do processo descolonização, con- 
texto em que não só se alteram certas correlações de força, como esse mundo passa a apresentar-se como uma série de ilhas invioláveis, diante da diversidade cultural apresentada. Com efeito, é o objeto que se rebela, transforma-se em sujeito; cidadãos do terceiro mundo prcocupados com a transformação e com a narrativa de sua própria história. No interior desse movimento altera-se - de reboque - a própria posição do antropólogo: o famoso "você está lá porque eu também estive", na versão crítica de Clifford Geertz.

Mais uma vez abriremos mão de entrar, diretamente, nessa seara. Nesse caso o que importa é mostrar de que maneira Marshall Sahlins foi também atingido, em sua condição de “antropólogo de um país central”. Seu livro How "Natives" Think. About Captain Cook for Example, publicado em 1995, é antes o resultado das reflexões que visaram rebater as críticas que Gananath Obeyesekere, um antropólogo nascido em Sri Lanka, lhe fez em seu livro The Apotheosis of Captain Cook: European Mythmaking in the Pacific (1992). Acusado de perpetuar mitos do imperialismo ocidental, de ver nos "nativos" havaianos apenas seres místicos - que só poderiam entender um estrangeiro como deus - e incapazes de produzir respostas pragmáticas, Sahlins foi questionado em sua capacidade e em seu direito de falar e fazer história dos "outros"; de traduzir um ponto de vista que não é seu.

Menos do que tomar partido, importa reter a reação de Sahlins, que ajuda a refletir sobre o lugar do antropólogo e a possibilidade que tem de falar sobre seu objeto. Em primeiro lugar, Sahlins questiona o "estatuto de nativo universal” a que Obeyesekere se arvora. Com que direito um "nativo" de Sri Lanka define Sahlins como “out-sider”, em relação aos povos do Pacífico? Ou seja, o que faria do ponto de vista de Obeyesekere um trunfoem termos de proximidade -, quando compa- rado à interpretação de Sahlins? Por outro lado, partindo do suposto que todos "os nativos são iguais", Obeyesekere procura neles apenas respostas racionais e pragmáticas. Ora, o que as obras de Sahlins sempre buscaram enfatizar foi a relação entre cosmologia e história; razão prática e simbólica, o que não é uma condição havaiana, mas, nos termos de Lévi-Strauss, um estatuto universal.

Os argumentos de Obeyesekere levariam, com efeito, a outro tipo de etnocentrismo. Se os havaianos seriam só, sempre e apenas, racionais, já os ocidentais, durante duzentos anos, permaneceriam incapazes de realizar algo além de reproduzir mitos e supor que os nativos os tomavam por deuses. Ao transformar a etnografia em fábula, Obeyesekere também pinta "seus nativos" de "burgueses realistas", fazendo deles o que somos. Mais uma vez, não se realiza boa história sem que se busque por "diferentes culturas, diferentes racionalidades".

A partir das reações de Sahlins seria possível recuperar a aposta de Lévi-Strauss em $O$ Pensamento Selvagem e sua reafirmação de uma humanidade plural em suas culturas e simbologias, mas universal em suas estruturas. Insistindo na tese de que os "nativos", como nós, não são só pragmáticos, racionais e instrumentais, "em relação à realidade empírica, Sahlins destaca a relação entre cosmologia e história e a importância da dimensão simbólica na análise política. Aos povos colonizados não resta apenas a “esperança” de deixar de pensar simbolicamente e passar a ter uma visão racional. Afinal, não há povo que não classifique e construa simbolicamente seus universos culturais. Em todas as sociedades reconhecemos, nos termos de Lévi-Strauss, a mão do bricoleur que coleciona objetos e a partir deles encontra uma lógica, e a ótica do engenheiro, que a partir de um projeto chega ao novo produto. 
Hora de terminar. Essa espécie de "pânico pós-moderno", ou, sem ironia, esse senso aguçado da diferença tem levado a um isolamento, a uma espécie de clamor de que cada um fale "por e em nome de sua cultura". Essa situação, por sua vez, tem gerado impasses e mudanças. Ela cobra da produção antropológica um engajamento social: é preciso repensar o processo de manipulação dos símbolos do poder e o nosso papel nesse sentido. No entanto, se os textos são instrumentos de poder e de prestígio, e somos questionados enquanto detentores das palavras que produzimos, Sahlins permite voltar à idéia de reversibilidade e pensar não na "coincidência", mas na "distância" que pode ser salutar na reflexão do pesquisador. Esse antropólogo ensina como é importante voltar à reflexão, como forma e instrumento de relativizar a dimensão do poder, que não é o único critério de validação de conhecimento. É a reflexibilidade que permite buscar não só a diferença, mas as persistências, e alargar a reflexão sobre o próprio “eu”. De alguma maneira nós somos iguais e humanos quando exigimos que a cultura produza sentido para a experiência humana. Desse ponto de vista, as construções equivalem-se e nossa igualdade é fundamental. É essa dimensão que corremos o risco de perder quando enfatizamos apenas e tão-somente a dimensão do poder, regendo e organizando a produção da cultura.

Se a Antropologia difere das ciências duras (sem querer menosprezar qualquer uma delas) é por causa da relação ambivalente que se impõe entre o "eu" e o "outro" e quando, pela mediação do espelho, é capaz de estabelecer um terceiro lugar de onde é possível observar a ambos. Esse é o lugar da humanidade. Com efeito, é a intersubjetividade que garante uma certa objetividade; é a combinação do reconhecimento da diversidade com a busca de invariantes que levará não a análi- ses irredutíveis, mas à possibilidade de buscar regras de tradução e de comunicação. Procurar pelas diversidades sob um fundo de indeferenciação, sem abrir mão das permanências, parece ainda servir como um bom lembrete, nesses momentos em que o registro da experiência passa a ser absolutizado.

As culturas são, com efeito, relativas umas em relação às outras, o que não significa, como bem mostrou Sahlins, cair em uma relatividade absoluta e impenetrável. A perspectiva que singulariza a disciplina parece ser, ainda - e enquanto não se invente fórmula melhor -, buscar uma matriz universal sob um grande inventário de culturas.

Diante da polêmica que marca os rumos recentes da disciplina, ao menos no contexto norte-americano, Sahlins tem assumido um papel importante ao não entrar no coro da, assim chamada, pós-modernidade. Fazer a crítica ao poder, e mostrar como não é possível colar-se à fala dos mais privilegiados, não deve levar a um discurso moral que implique a reprodução apaziguadora da fala de nossos “objetos feito sujeitos”. Não há por que optar, mesmo porque as culturas se utilizam de lentes que condicionam, até destoam, mas não impedem o olhar. Entre a longa e a curta duração, a estrutura e a conjuntura, a diacronia e a sincronia... f quemos com ambos os lados da moeda. Só assim será possível entender como as culturas não são uma simples soma de dois mais dois.

\section{Alguns Dados BiobibliográFICOS}

Marshall Sahlins nasceu em Chicago, Estados Unidos, em 1930. Fez a graduação e a pós-graduação em antropologia na Universidade de Michigan e em 1954 titulou-se Ph. D. pela Universidade de Columbia. A partir daí iniciou a sua carreira de professor universitário, lecionando em Michigan e em Columbia. 
Em 1973 chegou à Universidade de Chicago, onde leciona até hoje como Charles F. Grey Distinguished Service Professor Emeritus of Anthropology and Social Sciences. Em 1976 tornou-se membro da American Academy of Arts and Sciences. Sua obra traz importantes contribuições ao conhecimento etnográfico dos povos do Pacífico, às temáticas da evolução cultural e da antropologia econômica, além da relação entre cultura e história.

\section{PUBLICAÇÕES}

\section{Evolution and Culture}

1968 Tribesmen (Trad. bras.: Sociedades Tribais. Rio de Janeiro : Zahar, 1970)

1972 Stone Age Economics

1976 Culture and Practical Reason (Trad. bras.: Cultura e Razão Prática. Rio de Janeiro : Zahar, 1979)

1977 The Use e Abuse of Biology

1981 Historical Metaphors and Mylhical Realities. Structure in the Early History of Sandwich Islands Kingdom

1985 Islands of History (Trad. bras.: Ilhas de História. Rio de Janeiro : Zahar, 1989)

1992 Anahulu:The Anthropology of History in The Kingdom of Hawaii

1995 How "Natives" Think: About Captain Cook, for Example

\section{BIBLIOGRAFIA}

GEERTZ, Clifford. Local knowledge. Further essays in interpretative Anthropology. $1^{\text {a }}$ ed. New York: Basic Books Inc., 1983.

GEERTZ, Clifford. Works and Lives. The Anthropologist as Author. $1^{\text {a }}$ ed. Stanford : Stanford University Press, 1988.

LÉVI-STRAUSS, Claude. Raça e História. 1ª ed. Lisboa: Editorial Presença, 1952.

LÉVI-STRAUSS, Claude. "Etnologia e história". In: Antropologia estrutural. Tradução: Chaim Samuel Katz e Eginardo Pires; Revisão etnológica de Júlio Cezar Melatti. $4^{a}$ ed. Rio de Janeiro: Tempo Brasileiro, 1975.

LÉVI-STRAUSS, Claude. O Pensamento selvagem. Tradução: Maria Celeste da Costa e Souza e Almir de Oliveira Aguiar. 2a ed. São Paulo: Companhia Editora Nacional, 1976.

LÉVI-STRAUSS, Claude. A oleira ciumenta. Tradução: Editora Brasiliense S. A.; Revisão: Mario R. Q. Moraes ed Carlos Tomio Kurata. $1^{a}$ ed. São Paulo: Brasiliense, 1986.

MARCUS, George \& FISCHER, Michael. Anthropology as cultural critique. $1^{\mathrm{a}}$ ed. Chicago: The University of Chicago Press, 1986.

OBEYESEKERE, Gananath. The apotheosis of Captain Cook: european mythmaking in the Pacific. $1^{\text {a }}$ ed. Princeton: Princeton University Press, 1992.

MELATTI, Júlio Cezar (org.). Radcliffe-Brown: Antropologia. Tradução: Marcos A. L. de S. Coimbra e Orlando Pilatti. $1^{a}$ ed. São Paulo: Ática, 1978.

SAHLINS, Marshall. Cultura e razão prática. $1^{\text {a }}$ ed. Rio de Janeiro: Zahar, 1979.

SAHLINS, Marshall. Historical Metaphors and Mythical Realities. $2^{\mathrm{a}}$ ed. Ann Arbor: The University of Michigan Press, 1986.

SAHLINS, Marshall. Ilhas de História. $1^{\text {a }}$ ed. Rio de Janeiro: Jorge Zahar Editor, 1990.

SAHLINS, Marshall. How "Natives" think. About Captain Cook, for example. $1^{\text {a }} \mathrm{ed}$. Chicago: The University of Chicago Press, 1995.

SAHLINS, Marshall. "Introdução: História e teoria estrutural”. Cadernos de Campo, 9. , 2000a, p. 135-139.

SAHLINS, Marshall. “Conclusão: Estrutura na história”. Cadernos de Campo, n. 9, 2000b, p. 139-144. 